\title{
Loss Analysis and Air-Cooled Design for a Cascaded Electrical Source Transmitter
}

\author{
Kai-chang Xue*, Shuang Wang*, Jun Lin ${ }^{\dagger}$, Gang $\mathrm{Li}^{*}$, and Feng-dao Zhou* \\ ${ }^{*}$ College of Instrumentation and Electrical Engineering, Jilin University, Changchun, China
}

\begin{abstract}
Air-cooling method is adopted on the basis of the requirements for the thermal stability and convenient field use of an electrical source transmitter. The power losses of the transmitter are determined after calculating the losses of the alternating current (AC)-direct current (DC) power supply, the constant-current circuit, and the output circuit. According to the analysis of the characteristics of a heat sink with striped fins and a fan, the engineering calculation expression of the Nusselt number and the design process for air-cooled dissipation are proposed. Experimental results verify that the error between calculated and measured values of the transmitter losses is $12.2 \%$, which meets the error design requirements of less than $25 \%$. Steady-state average temperature rise of the heat sink of the AC-DC power supply is $22{ }^{\circ} \mathrm{C}$, which meets the design requirements of a temperature rise between $20{ }^{\circ} \mathrm{C}$ and $40{ }^{\circ} \mathrm{C}$. The transmitter has favorable thermal stability with $40 \mathrm{~kW}$ output power.
\end{abstract}

Key words: Air-cooled, Electrical source transmitter, Electromagnetic prospecting, Loss analysis

\section{NOMENCLATURE}

$A_{\mathrm{i}} \quad$ Area of baseplate outside, $\mathrm{m}^{2}$

$A_{\mathrm{o}} \quad$ Total surface area of fins, $\mathrm{m}^{2}$

$c_{\mathrm{a}} \quad$ Specific heat capacity of air, $\mathrm{J} /\left(\mathrm{kg}^{\circ} \mathrm{C}\right)$

$c_{1} \quad$ Stripe coefficient

C Perimeter of one fin, $\mathrm{m}$

d Hydraulic diameter of fin, $\mathrm{m}$

$E_{\text {off }} \quad$ Turn-off energy loss per pulse, J

$E_{\text {on }} \quad$ Turn-on energy loss per pulse, $\mathrm{J}$

$E_{\mathrm{rr}} \quad$ Reverse recovery energy loss per pulse, $\mathrm{J}$

$f \quad$ Friction factor

$f_{\text {app }} \quad$ Apparent friction factor

$h \quad$ Heat transfer coefficient, $\mathrm{W} /\left(\mathrm{m}^{2} \cdot{ }^{\circ} \mathrm{C}\right)$

$H \quad$ Height of fin, $\mathrm{m}$

$k_{\mathrm{a}} \quad$ Thermal conductivity of air, $\mathrm{W} /\left(\mathrm{m} \cdot{ }^{\circ} \mathrm{C}\right)$

$k_{\mathrm{f}} \quad$ Thermal conductivity of heat $\operatorname{sink}, \mathrm{W} /\left(\mathrm{m} \cdot{ }^{\circ} \mathrm{C}\right)$

$L \quad$ Heat sink length, $\mathrm{m}$

$L_{\mathrm{s}} \quad$ Heat source length, $\mathrm{m}$

$n \quad$ Rotational speed of fan, $\mathrm{r} / \mathrm{min}$

$n_{\mathrm{f}} \quad$ Fin number of heat sink

Manuscript received Jul. 18, 2014; accepted Oct. 13, 2014

Recommended for publication by Associate Editor Honnyong Cha.

${ }^{\dagger}$ Corresponding Author: lin_jun@jlu.edu.cn

Tel: +86-130-1910-0118, Jilin University

${ }^{*}$ College of Instrumentation and Electrical Eng., Jilin University, China $n_{\mathrm{m}} \quad$ Rate value of the rotational speed of fan, $\mathrm{r} / \mathrm{min}$

$N \quad$ Shaft power of fan, W

$N_{\mathrm{m}} \quad$ Rate value of the shaft power of fan, W

$\mathrm{Nu} \quad$ Nusselt number, $h s / k_{\mathrm{a}}$

NUT Number of transfer units

$p \quad$ Static pressure of fan, $\mathrm{Pa}$

$p_{\mathrm{m}} \quad$ Rate value of the static pressure of fan, $\mathrm{Pa}$

Pr Prandtl number, $\approx 0.7$ for air

$\Delta P_{\mathrm{a}} \quad$ Total pressure drop, $\mathrm{Pa}$

$\Delta P_{1} \quad$ Total pressure drop of inlet and outlet, $\mathrm{Pa}$

$\Delta P_{\mathrm{c}} \quad$ Core pressure drop, $\mathrm{Pa}$

$P \quad$ Power, W

$P_{\text {off }} \quad$ Turn-off loss, W

$P_{\text {on }} \quad$ Turn-on loss, W

$P_{\text {rr }} \quad$ Reverse recovery loss, $\mathrm{W}$

$Q \quad$ Volumetric flow rate, $\mathrm{m}^{3} / \mathrm{min}$

$Q_{\mathrm{m}} \quad$ Rate value of the volumetric flow rate of fan, $\mathrm{m}^{3} / \mathrm{min}$

$Q_{\mathrm{rr}} \quad$ Reverse recovery charge of diode, C

$R \quad$ Thermal resistance, ${ }^{\circ} \mathrm{C} / \mathrm{W}$

Re Reynolds number, $V_{\mathrm{a}} s / v$

$s \quad$ Fin spacing, $\mathrm{m}$

$t_{\mathrm{a}} \quad$ Fin thickness in root, $\mathrm{m}$

$t_{\mathrm{b}} \quad$ Baseplate thickness, $\mathrm{m}$

$T$ Temperature, ${ }^{\circ} \mathrm{C}$

$T_{\mathrm{a}} \quad$ Air temperature, ${ }^{\circ} \mathrm{C}$

$T_{\mathrm{f}} \quad$ Temperature of baseplate inside, ${ }^{\circ} \mathrm{C}$ 
$V_{\text {a }} \quad$ Average velocity in fin channel, $\mathrm{m} / \mathrm{s}$

$V_{\text {amax }}$ Maximum velocity in fin channel, $\mathrm{m} / \mathrm{s}$

$W \quad$ Heat sink width, $\mathrm{m}$

$W_{\text {s }} \quad$ Heat source width, $\mathrm{m}$

Greek Symbols

$\rho_{\mathrm{a}} \quad$ Air density, $\mathrm{kg} / \mathrm{m}^{3}$

$\rho_{\mathrm{P}} \quad$ Intensity of internal thermal source, $\mathrm{W} / \mathrm{m}^{3}$

$\eta \quad$ Efficiency of transmitter

$\eta_{\mathrm{f}} \quad$ Fin efficiency

$\eta_{\mathrm{a}} \quad$ Air viscosity under inlet and outlet average air temperature, $\mathrm{P}_{\mathrm{a}} \cdot \mathrm{s}$

$\eta_{\mathrm{a}} \quad$ Air viscosity under fin surface temperature, $\mathrm{Pa} \cdot \mathrm{s}$

$\varepsilon \quad$ Contraction ratio

$v \quad$ Kinematic viscosity, $\mathrm{m}^{2} / \mathrm{s}$

\section{INTRODUCTION}

Electromagnetic prospecting methods directly obtain underground information by using electromagnetic theory, which is widely used in water, mineral, and hydrocarbon resource explorations, as well as in other fields [1]-[3]. In controlled source audio-frequency magnetotelluric method, direct current resistivity method, and induced polarization method, the electrical source transmitter is the artificial excitation source for electromagnetic prospecting. The load of the electrical source transmitter is two electrode holes away from each other for $1-3 \mathrm{~km}$ on the ground, with an equivalent resistance of approximately $10-80 \Omega$. The transmitter must provide an exciting current to the earth load in practical applications, and the exciting current is approximately 10-40 A. Maximum output voltage usually needs to reach $1000 \mathrm{~V}$, and transmitter power usually needs to reach tens of $\mathrm{kW}$. For transmitters with a power of tens of $\mathrm{kW}$, thermal losses can reach several $\mathrm{kW}$.

Several transmitters have been developed in the field of geophysical instruments [4]-[8]. A transmitter developed by the Central South University of China and used for wide-area electromagnetic sounding has $200 \mathrm{~kW}$ output power [5]. The Institute of Geophysical and Geochemical Exploration under the Chinese Academy of Geological Sciences developed the DEM-T70 transmitter, which has $70 \mathrm{~kW}$ output power [7], [8]. An American company, Zonge International, developed the GGT-30 transmitter, which has $30 \mathrm{~kW}$ output power. These power devices of transmitters, used to acquire direct current (DC) bus voltage, work below $400 \mathrm{~Hz}$. These transmitters have high efficiency and output power. However, the system response speed is low, and the effect of suppressing transient earth load fluctuation should be improved. Therefore, these transmitters achieve high thermal stability at the cost of control precision. The Canadian Phoenix Company developed the TXU-30 transmitter. The power devices of TXU-30 work at $20 \mathrm{kHz}$, which has high control precision. However, China is the main area where electrical source transmitters are used, and
TXU-30 uses a three-phase $220 \mathrm{~V}$ generator instead of the three-phase $380 \mathrm{~V}$ mainstream generator used in China. Therefore, the thermal design of TXU-30 is not suitable for transmitters with $380 \mathrm{~V}$ input. In addition, the power of TXU-30 is $20 \mathrm{~kW}$, and its thermal losses are relatively low.

In the field of power electronics, research is focused on the loss calculation of power devices, whereas thermal dissipation analysis is comparatively scarce. The analysis method of thermal dissipation proposed in Ref. [9] involves several coefficients, but Ref. [9] does not show how to determine the coefficients, which limits its use for engineering applications. Ref. [10] disregards the effect of the efficiency of heat sink fin, and the thermal dissipation analysis is relatively rough. In Refs. [11]-[17], the analysis of heat sink is comprehensive, and several calculation expressions are introduced. However, the expressions proposed in these studies are generally complex, adding to the complexity of the engineering design. These studies also focus on a heat sink with smooth fins rather than the widely used one with striped fins. In the heat transfer field [18], thermal dissipation theories are systematically illustrated. However, these theories are generally macroscopic, and few studies show the corresponding analysis of air-cooled design on the basis of power circuit.

A heat sink with striped fins is analyzed in the present study on the basis of the characteristics of an electrical source transmitter, the classical theory of heat transfer, and the research results for heat sinks. Fan characteristics are studied based on the research results for hydromechanics. An engineering design process for air-cooled thermal dissipation is proposed. Experimental results verify that the transmitter has favorable thermal stability when the outputs are $1000 \mathrm{~V}$ and $40 \mathrm{~A}$. The calculation error of thermal losses of the transmitter and the temperature rise of the heat sink are reasonable. The proposed air-cooled method can be applied to other power electronic equipment below $100 \mathrm{~kW}$ to a certain extent.

This paper includes several symbols that are not easy to remember. Hence, the definitions of the main symbols are listed after the Abstract.

\section{DESIGN PURPoses}

The main purpose of the thermal design is to ensure the safety of devices in the transmitter, especially the security of power semiconductor devices. When the main purpose is met, another secondary purpose of the thermal design is considered. The secondary purpose is to ensure that the size and weight of the heat sink are as small as possible, making it convenient for field application.

For power semiconductor devices, the maximum allowable junction temperature of the tube core is generally $125^{\circ} \mathrm{C}$ $-150^{\circ} \mathrm{C}$. The maximum junction temperature $T_{\text {jmax }}$ can be obtained from device specifications, and the junction temperature is represented as $T_{\mathrm{j}}$ or $T_{\mathrm{vj}}$ in device specifications. 
TABLE I

FAn PARAmeters of Delta COMPANy

\begin{tabular}{cccc}
\hline Size $(\mathbf{c m})$ & $\boldsymbol{N}_{\mathbf{m}}(\mathbf{W})$ & $\boldsymbol{Q}_{\mathbf{m}}\left(\mathbf{m}^{\mathbf{3}} / \mathbf{m i n}\right)$ & $\boldsymbol{p}_{\mathbf{m}}(\mathbf{P a})$ \\
\hline $12 \times 12 \times 3.8$ & $1.7-48$ & $2.02-7.16$ & $41.4-352$ \\
$9.2 \times 9.2 \times 3.8$ & $4.0-37$ & $1.93-4.95$ & $76.0-453$ \\
$8 \times 8 \times 3.8$ & $2.4-18$ & $1.28-2.89$ & $69.9-307$ \\
$6 \times 6 \times 2.54$ & $0.84-9.0$ & $0.541-1.45$ & $32.0-253$ \\
\hline
\end{tabular}

The temperature loss, $\Delta T_{1}$, between the tube core and the case of the device is $10{ }^{\circ} \mathrm{C}-25^{\circ} \mathrm{C} . \Delta T_{1}=P \cdot R_{\mathrm{thJC}}$, where $P$ represents the power loss of the device, and $R_{\mathrm{thJC}}$ represents the thermal resistance between the tube core and the case. $R_{\mathrm{thJC}}$ can be obtained from device specifications, and some specifications also adopt $R_{\mathrm{th}(\mathrm{j}-\mathrm{c})}$. Insulation pad, contact gap, and so on will induce a loss, $\Delta T_{2}$, of $10{ }^{\circ} \mathrm{C}-25^{\circ} \mathrm{C}$ between the device and the heat sink. For power modules, the case is generally insulated against device pins. $\Delta T_{2}=P \cdot R_{\mathrm{thCK}}$, where $R_{\mathrm{thCH}}$ represents the contact thermal resistance between the case and the heat sink. $R_{\text {thCK }}$ can be obtained from device specifications, and some specifications also adopt $R_{\mathrm{th}(\mathrm{c}-\mathrm{k})}$. For discrete power devices, the case is generally connected to one pin of a device. Thus, an insulation pad should be added between the case and the heat sink. $\Delta T_{2}=P \cdot\left(R_{\mathrm{thCK}}+R_{\mathrm{ic}}\right)$, where $R_{\mathrm{ic}}$ represents the thermal resistance of the insulation pad. The calculation of $R_{\mathrm{ic}}$ will be shown in Section IV.A. The local temperature of the heat sink where the power device is located is higher than the average temperature of the heat sink, and the temperature loss $\Delta T_{3}$ is approximately $10^{\circ} \mathrm{C} . \Delta T_{3}=P \cdot R_{\mathrm{cb}}$. The calculation of $R_{\mathrm{cb}}$ will be shown in Section IV.A, which is from Ref. [17]. The maximum temperature $T_{\text {amax }}$ in the field in summer may be $35{ }^{\circ} \mathrm{C}-38{ }^{\circ} \mathrm{C}$. Therefore, the average temperature rise $\Delta T_{\mathrm{hs}}$ of the heat sink should be less than $40^{\circ} \mathrm{C}$, where $\Delta T_{\mathrm{hs}}=T_{\text {jmax }}-\Delta T_{1}-\Delta T_{2}-\Delta T_{3}-T_{\text {amax }}$. Although a low temperature rise will increase the reliability of the devices, it will also increase the size and weight of the heat sink. A significantly low temperature rise does more harm than good. Therefore, the temperature rise should be kept between $20^{\circ} \mathrm{C}$ and $40{ }^{\circ} \mathrm{C}$.

To control the temperature rise of the heat sink, the device losses should be calculated. When loss error is too high, the selected heat sink will be obviously small or large. The small size of the heat sink will cause a high temperature rise, which endangers the safety of the devices. The large size of the heat sink will cause the transmitter to become very heavy. Given that the power dissipation of the heat sink is approximately proportional to the size and weight of the heat sink with the same structure and with the size difference below several tens of percent (Figs. 2(d) and 5(a) in Ref. [19]), the loss error between $0 \%$ and $+25 \%$ does not significantly increase the transmitter weight. Volumetric flow rate $Q_{\mathrm{m}}$ and static pressure $p_{\mathrm{m}}$ are also different for same-sized fans, as shown in Table I [20]. $Q \propto P / \Delta T_{\mathrm{a}}$, where $P$ represents the power loss, $Q$ represents the volumetric flow rate of the fan, and $\Delta T_{\mathrm{a}}$

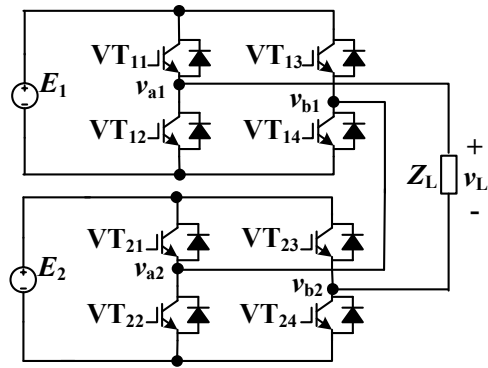

Fig. 1. Principle of the cascaded topology.

TABLE II

SWITCHING LOSSES OF DIFFERENT IGBTS

\begin{tabular}{|c|c|c|c|c|c|c|}
\hline \multirow{2}{*}{$\begin{array}{c}\text { Loss } \\
\text { categories }\end{array}$} & \multicolumn{2}{|c|}{$600 \mathrm{~V}$} & \multicolumn{2}{c|}{$1200 \mathrm{~V}$} & \multicolumn{2}{c|}{$3300 \mathrm{~V}$} \\
\cline { 2 - 7 } & $Q_{\text {rate }}$ & $Q_{\text {/kW }}$ & $Q_{\text {rate }}$ & $Q_{\text {/kW }}$ & $Q_{\text {rate }}$ & $Q_{\text {/kW }}$ \\
\hline$E_{\text {on }}(\mathrm{mJ})$ & 1.6 & 0.05 & 9 & 0.15 & 170 & 0.94 \\
\hline$E_{\text {off }}(\mathrm{mJ})$ & 4.0 & 0.13 & 12 & 0.20 & 140 & 0.78 \\
\hline$E_{\text {rr }}(\mathrm{mJ})$ & 3.0 & 0.10 & 12.4 & 0.21 & 185 & 1.03 \\
\hline
\end{tabular}

represents the temperature difference between inlet and outlet air. The error can be feasibly and easily compensated by replacing the fan with the same size when the loss error is between $0 \%$ and $-25 \%$. A low loss error needs a highly accurate mathematical model and must consider numerous factors [21]-[23]. Some stray losses are difficult to calculate, and the actual conditions are not exactly the same as the testing conditions in the specification. These conditions include voltage [21], current [21], junction temperature [21], device driver [22], pulse width [23], and circuit topologies. Therefore, selecting $25 \%$ as the accepted loss error is a relatively reasonable trade-off between application value and calculation complexity.

\section{TRANSMITTER LOSSES}

\section{A. Cascaded Topology of the Transmitter}

The transmitter adopts the cascaded topology shown in Fig. 1 , where $Z_{\mathrm{L}}$ represents the earth load of the transmitter. When $\mathrm{VT}_{11}, \mathrm{VT}_{14}$ and $\mathrm{VT}_{21}, \mathrm{VT}_{24}$ turn on, the load voltage is $v_{\mathrm{L}}=E_{1}+E_{2}=2 E$, and the output is a positive pulse. When $\mathrm{VT}_{12}, \mathrm{VT}_{13}$ and $\mathrm{VT}_{22}, \mathrm{VT}_{23}$ turn on, the load voltage is $v_{\mathrm{L}}=-\left(E_{1}+E_{2}\right)=-2 E$, and the output is a negative pulse. The output level of the transmitter is only $+2 E$ and $-2 E$ without $+E,-E$, and 0 , which is different from the conventional cascaded multilevel inverters [24]-[26]. $E_{1}$ and $E_{2}$ are in a floating state that refers to the load $Z_{\mathrm{L}}$. Therefore, the rated voltage of the insulated gate bipolar transistors (IGBTs) can be half of the integrated transmitter, which can reduce the design difficulty and the switching losses of the transmitter.

Table II shows the relationship between maximum rated voltage and switching losses of different IGBTs. In Table II, the switching loss parameters of 600,1200 , and $3300 \mathrm{~V}$ IGBTs are from the IGBT modules marked FF200R06KE3, FF200R12KT4, and FF200R33KF2C, respectively. $E_{\text {on }}, E_{\text {off }}$, 


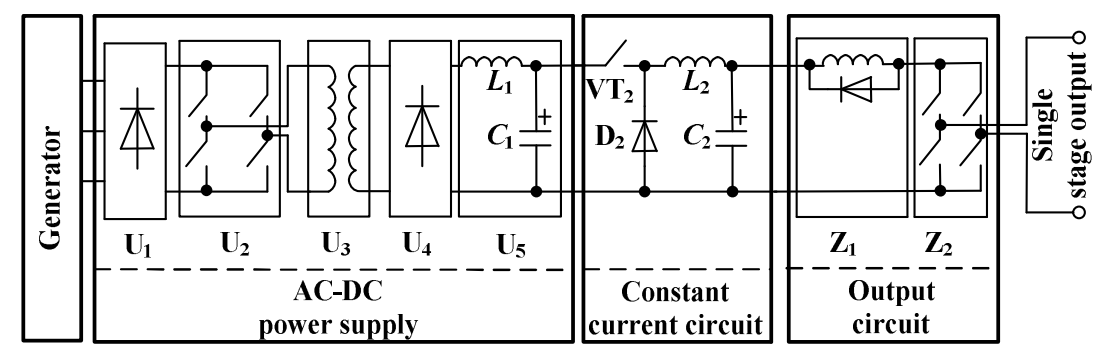

Fig. 2. Circuit diagram of a single-stage transmitter.

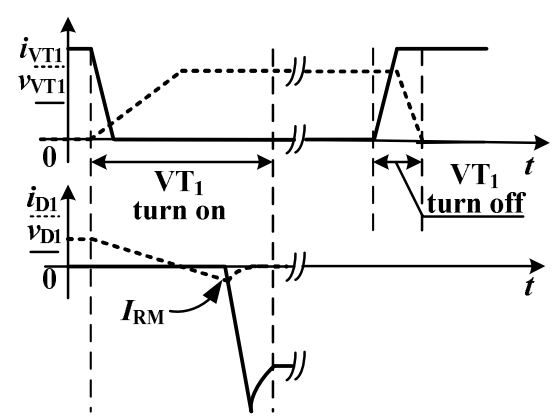

(a)

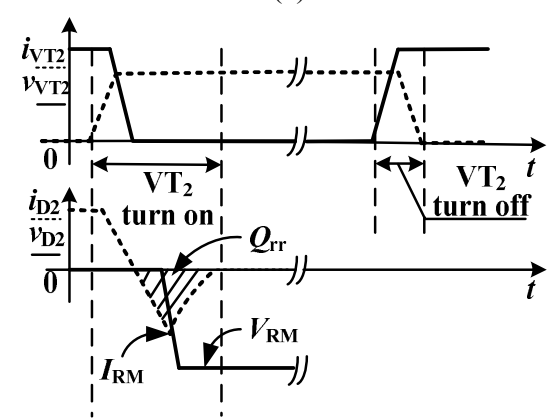

(b)

Fig. 3. Switching loss analysis. (a) AC-DC power supply. (b) The constant-current circuit.

and $E_{\mathrm{rr}}$ represent turn-on, turn-off, and diode reverse recovery energy losses per pulse, respectively. $Q_{\text {rate }}$ is the energy losses under the rated power. For 600,1200 , and $3300 \mathrm{~V}$ IGBTs, the rated powers are $300 \mathrm{~V} / 100 \mathrm{~A}, 600 \mathrm{~V} / 100 \mathrm{~A}$, and $1800 \mathrm{~V} / 100 \mathrm{~A}$, respectively. For comparison, the energy losses are normalized to per $\mathrm{kW}$, which is represented as $\mathrm{Q}_{\mathrm{kW}}$ in Table II. Table II shows that the switching losses of $600 \mathrm{~V}$ IGBT are approximately half of those of $1200 \mathrm{~V}$ IGBT. Meanwhile, the switching losses of $3300 \mathrm{~V}$ IGBT are approximately five times those of $1200 \mathrm{~V}$ IGBT. Therefore, cascaded topology can reduce switching losses.

The circuit of the single-stage transmitter involved in the cascaded technology is shown in Fig. 2. The AC-DC power supply converts the $380 \mathrm{~V}$ AC provided by the generator to $550 \mathrm{~V} \mathrm{DC}$, and the high-frequency transformer isolates the input and the output. The constant-current circuit makes the average current in the chopper inductance $L_{2}$ the set value by adjusting the chopper-circuit switch $\mathrm{VT}_{2}$; that is, it maintains the output current of the chopper circuit at the set value. The output full-bridge $Z_{2}$ of the output circuit with another output full bridge in another single-stage transmitter comprises the cascaded topology shown in Fig. 1.

\section{B. Single-Stage Transmitter Losses}

Considering that the entire electrical source transmitter consists of two single-stage transmitters in series, only the thermal losses of the single-stage transmitter must be analyzed. 1) Switching Losses: When any IGBT of the four IGBTs involved in the full-bridge inverter $\mathrm{U}_{2}$ is represented as $\mathrm{VT}_{1}$, any diode of the high-frequency rectifier $\mathrm{U}_{4}$ is represented as $\mathrm{D}_{1}$, the chopper switch IGBT is represented as $\mathrm{VT}_{2}$, and the chopper diode is represented as $\mathrm{D}_{2}$. The voltage and current waveforms of IGBTs and diodes during the turn-on and turn-off are shown in Fig. 3. In Fig. 3, $i_{\mathrm{VT} 1}$ and $v_{\mathrm{VT} 1}$ represent the current and voltage of $\mathrm{VT}_{1}$ when $\mathrm{VT}_{1}$ turns on and turns off respectively. $i_{\mathrm{D} 1}$ and $v_{\mathrm{D} 1}$ represent the current and voltage of $\mathrm{D}_{1}$ during the reverse recovery respectively. $i_{\mathrm{VT} 2}$ and $v_{\mathrm{VT} 2}$ represent the current and voltage of $\mathrm{VT}_{2}$ when $\mathrm{VT}_{2}$ turns on and turns off respectively. $i_{\mathrm{D} 2}$ and $v_{\mathrm{D} 2}$ represent the current and voltage of $\mathrm{D}_{2}$ during the reverse recovery respectively.

In Fig. 3(a), the overlapping area between $i_{\mathrm{VT} 1}$ and $v_{\mathrm{VT} 1}$ is small when $\mathrm{VT}_{1}$ turns on because the leakage inductance of the transformer suppresses the changing rate of the current. The slope of the diode current $i_{\mathrm{D} 1}$ is relatively low when $i_{\mathrm{D} 1}$ drops from the positive steady-state current $I_{\mathrm{F}}$ to the maximum reverse value $-I_{\mathrm{RM}}$. The overlapping area between $i_{\mathrm{D} 1}$ and $v_{\mathrm{D} 1}$ is small. This situation is not in accordance with the test conditions for the turn-on loss of the IGBT in the specifications. Therefore, the turn-on loss of $\mathrm{VT}_{1}$ and the reverse recovery loss of $D_{1}$ are lower than the turn-off energy loss $E_{\mathrm{on}}$ and the reverse recovery energy loss $E_{\mathrm{rr}}$ in the specification. When $\mathrm{VT}_{1}$ turns off, no other circulation loop exists, except $\mathrm{VT}_{1}$ for the current in the primary side of the transformer before the voltage $v_{\mathrm{VT} 1}$ rises from 0 to bus voltage. Therefore, $i_{\mathrm{VT} 1}$ remains the initial current value, and the overlapping area between $i_{\mathrm{VT} 1}$ and $v_{\mathrm{VT} 1}$ is large. The turn-off is in accordance with the test conditions in the specifications. Therefore, the turn-off energy loss $E_{\text {off }}$ can be used to calculate the turn-off loss.

In Fig. 3(b), the overlapping area between $i_{\mathrm{VT} 2}$ and $v_{\mathrm{VT} 2}$ is large when $\mathrm{VT}_{2}$ turns on because $v_{\mathrm{VT} 2}$ is clamped to the input voltage before $i_{\mathrm{VT} 2}$ rises from 0 to the steady-state value. The 
TABLE III

AC-DC POWER SUPPLy LOSSES

\begin{tabular}{cccc}
\hline Symbols & Losses $(\mathbf{W})$ & Symbols & Losses $(\mathbf{W})$ \\
\hline$P_{\mathrm{U} 1}$ & 190 & $P_{\mathrm{L} 1}$ & 50 \\
$P_{\mathrm{U} 2}$ & $4 \times 137$ & $P_{\mathrm{U} 6}$ & 110 \\
$P_{\mathrm{U} 2 \mathrm{R}}$ & $4 \times 7$ & $P_{\mathrm{U} 7}$ & $24 \times 2$ \\
$P_{\mathrm{U} 3}$ & 72 & $P_{\mathrm{U} 8}$ & 50 \\
$P_{\mathrm{U} 4}$ & $8 \times 52$ & $P_{\mathrm{U} 9}$ & 100 \\
$P_{\mathrm{U} 4 \mathrm{R}}$ & 76 & & \\
\hline
\end{tabular}

changing rate that the current $i_{\mathrm{D} 2}$ in diode $\mathrm{D}_{2}$ decreases from the positive steady-state current $I_{\mathrm{F}}$ to 0 is determined by the inherent rate of the IGBT. The changing rate of the IGBT inherent current is fast when it turns on. Therefore, the peak value $I_{\mathrm{RM}}$ of the reverse recovery current of the diode $\mathrm{D}_{2}$ is large. The overlapping area between $i_{\mathrm{D} 2}$ and $v_{\mathrm{D} 2}$ is also large. When $\mathrm{VT}_{2}$ turns off, the current of chopper inductance $L_{2}$ can only flow through $\mathrm{VT}_{2}$ before the voltage $v_{\mathrm{VT} 2}$ increases from 0 to the input voltage. Therefore, the overlapping area between $i_{\mathrm{VT} 2}$ and $v_{\mathrm{VT} 2}$ is large. The turn-on and turn-off of $\mathrm{VT}_{2}$ and the reverse recovery of the diode $\mathrm{D}_{2}$ are in accordance with the specifications of IGBT test conditions. $E_{\text {on }}, E_{\text {off }}$, and $E_{\mathrm{rr}}$ can thus be used to calculate $\mathrm{VT}_{2}$ and $\mathrm{D}_{2}$ losses.

For the IGBTs involved in the output full-bridge $Z_{2}$ in the output circuit, the turn-off process is consistent with that of $\mathrm{VT}_{1}$. The turn-off energy loss $E_{\text {off }}$ can be used to calculate the turn-off loss. The turn-on process is also consistent with that of $\mathrm{VT}_{1}$. However, the load inductance is larger than the leakage inductance of the transformer. Turn-on loss is lower than that of $\mathrm{VT}_{1}$, which can thus be ignored.

Eq. (1) can be used to calculate the corresponding switching losses when the situation is equivalent to the test conditions in the specification. It is expressed as follows:

$$
P_{\mathrm{x}}=E_{\mathrm{x}} \cdot f_{\mathrm{S}} \cdot\left(V / V_{\mathrm{REF}}\right) \cdot\left(I / I_{\mathrm{REF}}\right),
$$

where $\mathrm{x}$ can be on, off, or rr, which respectively represents the turn-on of the IGBT, turn-off of the IGBT, or reverse recovery of the diode. $E_{\mathrm{x}}$ represents the energy losses with the testing voltage $V_{\mathrm{REF}}$ and the testing current $I_{\mathrm{REF}}$ in the specification. $V$ and $I$ represent the actual working voltage and current of the power device respectively. $P_{\mathrm{x}}$ represents the power losses. $f_{\mathrm{s}}$ represents the switching frequency.

For some diodes, the specification does not give $E_{\mathrm{rr}}$. Eq. (2) can be used to calculate $E_{\mathrm{rr}}$ of the diode, that is,

$$
E_{\mathrm{rr}}=V_{\mathrm{RM}} Q_{\mathrm{rr}} / 2 \text {, }
$$

where $V_{\mathrm{RM}}$ is the reverse steady-state voltage of the diode. $Q_{\mathrm{rr}}$ is the reverse recovery charge, which can be found in the specification.

2) Total Losses: The output of the AC-DC power supply is designed to be $550 \mathrm{~V}$ and $45 \mathrm{~A}$, and the power is $25 \mathrm{~kW}$. The $50 \mathrm{~Hz}$ rectifier $\mathrm{U}_{1}$ of the AC-DC power supply adopts VUO110-16NO7, the input contactor adopts CJX2-6511, and the full-bridge inverter $\mathrm{U}_{2}$ adopts the IGBT module FF200R12KT4, which operates in $18 \mathrm{kHz}$. The high-frequency rectifier $\mathrm{U}_{4}$ adopts a full-bridge rectifier, and the single-bridge leg consists of four diodes in series, which adopt the diode module MEE250-012DA. The full-bridge inverter $U_{2}$ adopts the resistor-capacitor (RC) snubber circuit to eliminate resonance. Each IGBT parallels an RC snubber, with $R$ of $100 \Omega$ and $C$ of $3.3 \mathrm{nF}$. The high-frequency transformer $\mathrm{U}_{3}$ adopts 3 EE110 cores in parallel, 7 turns in primary, and 10 turns in secondary. Each turn in primary and secondary uses double Liz wires, $\Phi 0.1 \mathrm{~mm} \times 800$, in parallel. The high-frequency rectifier $\mathrm{U}_{4}$ also adopts an RC snubber, with $R$ of $50 \Omega$ and $C$ of $6.8 \mathrm{nF}$. The RC snubber parallels the secondary of the high-frequency transformer $\mathrm{U}_{3}$, and the output inductance $L_{1}$ adopts four EE110 cores in parallel. The air gap is $12.8 \mathrm{~mm}$, and the number of turns is 27 . Each turn uses double Liz wires, $\Phi 0.1 \mathrm{~mm} \times 800$, in parallel. Table III shows the calculated value of the AC-DC power supply losses.

In Table III, $P$ represents the losses, the subscript $\mathrm{U}_{1}$ represents the $50 \mathrm{~Hz}$ rectifier, $\mathrm{U}_{2}$ represents the full-bridge inverter, $U_{2 R}$ represents the snubber resistance of the full-bridge inverter $U_{2}, U_{3}$ represents the high-frequency transformer, $U_{4}$ represents the high-frequency rectifier, $U_{4 R}$ represents the RC snubber resistance of the high-frequency rectifier, $L_{1}$ represents the output inductor, $\mathrm{U}_{6}$ represents the fan and its power supply, $U_{7}$ represents the resistance used to balance the voltage of the series capacitor $C_{1}, \mathrm{U}_{8}$ represents the input contactor, and $\mathrm{U}_{9}$ represents other stray losses. The losses of $\mathrm{U}_{1}, \mathrm{U}_{2}, \mathrm{U}_{2 \mathrm{R}}, \mathrm{U}_{4}$, and $\mathrm{U}_{4 \mathrm{R}}$ are $1258 \mathrm{~W}$. These devices are fixed on a heat sink. The total losses of the AC-DC power supply are $1688 \mathrm{~W}$. The efficiency of the AC-DC power supply is $93.2 \%$.

The constant-current circuit output is designed to be $500 \mathrm{~V}$ and $50 \mathrm{~A}$, and the power is $25 \mathrm{~kW}$. The working frequency of the chopper circuit is $18 \mathrm{kHz}$. The chopper switch $\mathrm{VT}_{2}$ and the chopper diode $\mathrm{D}_{2}$ adopt the internal integration devices of the IGBT module FF200R12KT4. The constant-current inductance $L_{2}$ is in accordance with the output inductance $L_{1}$ of the AC-DC power supply. The diode of the short-circuit protection circuit $Z_{1}$ adopts MEK250-12DA, which has two parallel internal diodes. The inductance of the short-circuit protection circuit $Z_{1}$ adopts nine EE55 cores in parallel, the air gap is $2.25 \mathrm{~mm}$, and the number of turns is 7.5. Each turn uses double Liz wires, $\Phi 0.1 \mathrm{~mm} \times 800$, in parallel. The full-bridge $Z_{2}$ adopts the IGBT module 2MBI200U4H-170. Each IGBT parallels an RC snubber, with $R$ of $100 \Omega$ and $C$ of $3.3 \mathrm{nF}$. The working frequency is $1-10 \mathrm{kHz}$. Given that the load is inductive, the current generally cannot be more than $20 \mathrm{~A}$ when the transmitting frequency of the output full-bridge $Z_{2}$ is higher than $1 \mathrm{kHz}$. Therefore, $2 \mathrm{kHz}$ and $20 \mathrm{~A}$ are adopted to calculate the losses of $Z_{1}$ and the output full-bridge $Z_{2}$. Table IV shows the calculated losses of the constant-current circuit and the output circuit.

In Table IV, $P$ represents the losses, the subscript $\mathrm{VT}_{2}$ represents the chopper switch, $\mathrm{D}_{2}$ represents the chopper 
TABLE IV

Losses of CONSTANT-CurRent CiRCuit AND Output Circuit

\begin{tabular}{cccc}
\hline Symbols & Losses $(\mathbf{W})$ & Symbols & Losses $(\mathbf{W})$ \\
\hline$P_{\mathrm{VT} 2}$ & 223 & $P_{\mathrm{Z} 2}$ & $4 \times 47$ \\
$P_{\mathrm{D} 2}$ & 132 & $P_{\mathrm{Z} 2 \mathrm{R}}$ & $4 \times 4$ \\
$P_{\mathrm{L} 2}$ & 50 & $P_{\mathrm{Z} 3}$ & $24 \times 2$ \\
$P_{\mathrm{Z} 1 \mathrm{D}}$ & 60 & $P_{\mathrm{Z} 4}$ & 110 \\
$P_{\mathrm{Z} 1 \mathrm{~L}}$ & 17 & $P_{\mathrm{Z} 5}$ & 100 \\
\hline
\end{tabular}

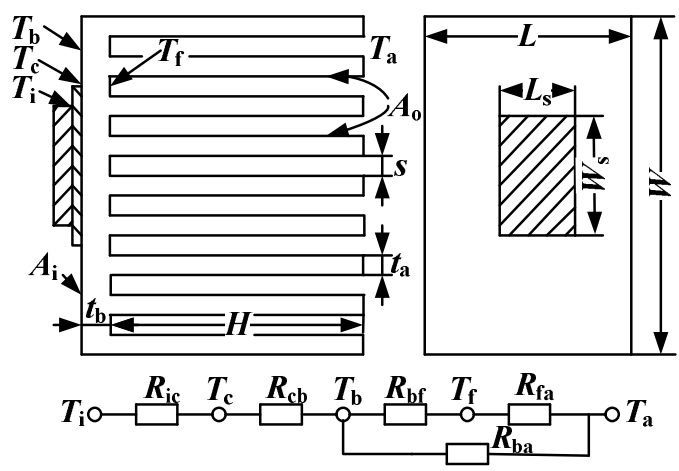

Fig. 4. Thermal resistance model.

diode, $L_{2}$ represents the inductance of the constant-current circuit, $Z_{1 D}$ represents the diode of the short-circuit protection circuit, $Z_{1 \mathrm{~L}}$ represents the short-circuit protection inductance, $Z_{2}$ represents the output full bridge, $Z_{2 R}$ represents the $R C$ snubber of the full-bridge $Z_{2}, Z_{3}$ represents the resistance used to balance the voltage of series capacitor $C_{2}, Z_{4}$ represents the fan and its power supply, and $Z_{5}$ represents other stray losses. The total losses of the constant-current circuit and the output circuit are $944 \mathrm{~W}$. The losses of $\mathrm{VT}_{2}$, $D_{2}, Z_{1 D}, Z_{1 L}, Z_{2}$, and $Z_{2 R}$ are $619 \mathrm{~W}$. These devices are fixed on a heat sink. Therefore, the comprehensive efficiency of the constant-current circuit and the output circuit is $96.2 \%$.

The preceding analysis indicates that the design losses of the single-stage transmitter are $2632 \mathrm{~W}$, and the efficiency is $89.5 \%$.

\section{AIR-COOLED DESIGN}

\section{A. Thermal Resistance Model}

Fig. 4 shows the thermal resistance model. The length and width of the heat source are $L_{\mathrm{s}}$ and $W_{\mathrm{s}}$ respectively. The heat source is attached to the heat sink with the insulation pad. The length and width of the heat sink are $L$ and $W$ respectively. The height of the fin and the thickness in the root are $H$ and $t_{\mathrm{a}}$ respectively. The fin spacing is $s . A_{\mathrm{i}}$ is the area of the outside of the baseplate, and $A_{\mathrm{o}}$ is the total surface area of the fins. The thickness of the baseplate is $t_{\mathrm{b}}$. The equivalent circuit of thermal resistance is shown at the bottom of Fig. 4. $T_{\mathrm{i}}, T_{\mathrm{c}}, T_{\mathrm{b}}$, $T_{\mathrm{f}}$, and $T_{\mathrm{a}}$ represent the temperature of the heat source, the baseplate side of the insulation pad, the outer surface of the baseplate, the inside of the baseplate, and the air, respectively. $R_{\mathrm{ic}}, R_{\mathrm{cb}}, R_{\mathrm{bf}}, R_{\mathrm{fa}}$, and $R_{\mathrm{ba}}$ represent the thermal resistance of the
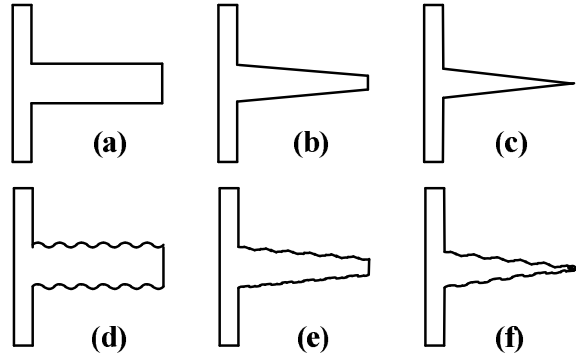

Fig. 5. Heat sink fins. (a) Straight fin. (b) Trapezoidal fin. (c) Triangular fin. (d) Straight fin with stripes. (e) Trapezoidal fin with stripes. (f) Triangular fin with stripes.

insulation pad, the insulation pad to the outer surface of the baseplate, the baseplate, the fins to the air, and the outer surface of the baseplate to the air [17].

$$
R_{\mathrm{ic}}=t_{\mathrm{c}} /\left(k_{\mathrm{c}} L_{\mathrm{s}} W_{\mathrm{s}}\right),
$$

where $t_{\mathrm{c}}$ and $k_{\mathrm{c}}$ represent the thickness and the thermal conductivity of the insulation pad respectively.

$$
\begin{aligned}
R_{\mathrm{cb}} & =\frac{8}{L_{\mathrm{s}}^{2} L W k_{\mathrm{f}}} \sum_{m=1}^{\infty} \frac{\sin ^{2}\left(\delta_{m} L_{\mathrm{s}} / 2\right)}{\delta_{m}^{3}} \cdot \phi\left(\delta_{m}\right) \\
& +\frac{8}{W_{\mathrm{s}}^{2} L W k_{\mathrm{f}}} \sum_{n=1}^{\infty} \frac{\sin ^{2}\left(\lambda_{n} W_{\mathrm{s}} / 2\right)}{\lambda_{n}^{3}} \cdot \phi\left(\lambda_{n}\right) \\
& +\frac{16}{L_{\mathrm{s}}^{2} W_{\mathrm{s}}^{2} L W k_{\mathrm{f}}} \sum_{m=1}^{\infty} \sum_{n=1}^{\infty} \frac{\sin ^{2}\left(\delta_{m} L_{\mathrm{s}} / 2\right) \sin ^{2}\left(\lambda_{n} W_{\mathrm{s}} / 2\right)}{\delta_{m}^{2} \lambda_{n}^{2} \beta_{m, n}} \phi\left(\beta_{m, n}\right)
\end{aligned}
$$

where

$$
\begin{gathered}
\phi(\zeta)=\frac{\left(e^{2 t_{\mathrm{b}} \zeta}+1\right) \zeta-\left(1-e^{2 t_{\mathrm{b}} \zeta}\right) h_{\mathrm{eff}} / k_{\mathrm{f}}}{\left(e^{2 t_{\mathrm{b}} \zeta}-1\right) \zeta-\left(1+e^{2 t_{\mathrm{b}} \zeta}\right) h_{\mathrm{eff}} / k_{\mathrm{f}}}, \\
h_{\text {eff }}=h A_{\mathrm{o}} \eta_{\mathrm{f}} / A_{\mathrm{i}},
\end{gathered}
$$

$h$ is the heat transfer coefficient of the heat sink to air. $\eta_{\mathrm{f}}$ is the efficiency of the heat sink, $\delta_{\mathrm{m}}=2 m \pi / L, \quad \lambda_{\mathrm{m}}=2 n \pi / W$, $\beta_{m, n}=\left(\delta_{m}^{2}+\lambda_{n}^{2}\right)^{1 / 2}$, and $k_{\mathrm{f}}$ is the thermal conductivity of the heat sink

$$
\begin{gathered}
R_{\mathrm{bf}}=t_{\mathrm{b}} /\left(k_{\mathrm{f}} A_{\mathrm{i}}\right) \\
R_{\mathrm{ba}}=1 /\left(h A_{\mathrm{i}}\right) \\
R_{\mathrm{fa}}=1 /\left(h A_{\mathrm{o}} \eta_{\mathrm{f}}\right)
\end{gathered}
$$

\section{B. Efficiency of Striped Fins}

The shapes of common heat sink fins, including rectangular, trapezoidal, and triangular fins, are shown in Fig. 5. Stripes are usually engraved on fins to increase the surface area of thermal dissipation in engineering applications. Refs. [11]-[18] provided some calculation methods for smooth fins. However, few reports have discussed the effect of striped fins. The efficiency of striped fins will be analyzed in the following section on the basis of the known analysis of smooth fin.

For the heat sink of thermal dissipation power above $100 \mathrm{~W}$, air velocity $V_{\mathrm{a}}$ in the fin channel is lower than $5 \mathrm{~m} / \mathrm{s}$, 

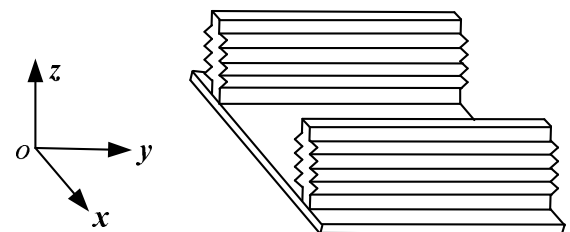

(a)

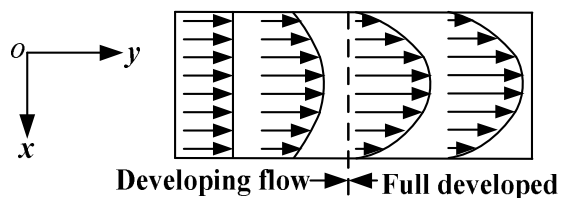

(b)

Fig. 6. Laminar flow in striped fin channel.

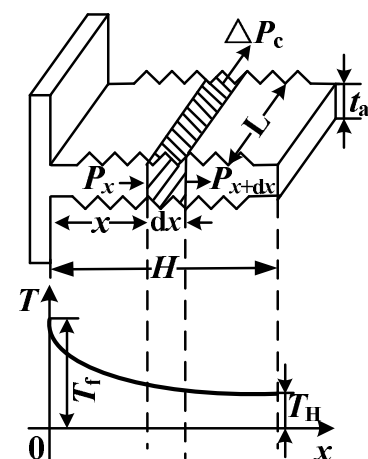

(a)

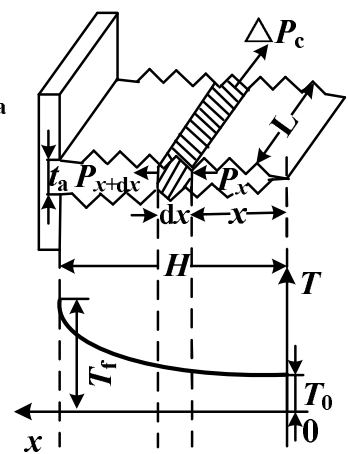

(b)
Fig. 7. Analysis diagram of the efficiency of striped fins. (a) Straight fin analysis. (b) Triangular fin analysis.

and fin spacing $s$ is lower than $7 \times 10^{-3} \mathrm{~m}$ in general. Air kinematic viscosity $v$ is approximately $17 \times 10^{-6} \mathrm{~m}^{2} / \mathrm{s}$ and around $\quad 40^{\circ} \mathrm{C}$. Therefore, Reynolds number $R e=V_{\mathrm{a}} \cdot s / v<2200$, and the air flow in the fin channel is laminar flow [18]. Fig. 6 shows the laminar flow in the striped fin channel. When the air flows in the fin channel along $y$ direction, given that the direction of the stripe groove coincides with the direction of the air flow, the striped fin cannot change the air flow direction. The air only flows in the $x O y$ plane, as shown in Fig. 6(b). The air velocity is uniform at $x$ direction in inlet. When air from the developing flow section enters the fully developed section, the air velocity is larger in the middle and lower in both sides. The nature of air flow in striped fins and smooth fins is the same.

The main difference between striped and smooth fins is the surface area of the fins. The stripe coefficient $c_{1}$ in Eq. (8) can be used to express the difference, that is,

$$
c_{1}=A_{\mathrm{o}} /\left(2 n_{\mathrm{f}} L H\right),
$$

where $A_{\mathrm{o}}$ represents the total surface area of the fins, and $n_{\mathrm{f}}$ represents the fin number of the heat sink.

Fig. 7 shows the 1D analysis model of the efficiency of striped fins. According to the thermal conduction differential equation,

$$
\frac{\mathrm{d}}{\mathrm{d} x}\left[A_{\mathrm{f}}(x) \frac{\mathrm{d} T}{\mathrm{~d} x}\right]+\frac{\rho_{\mathrm{P}}}{k_{\mathrm{f}}}=0,
$$

where $T$ is the temperature variable, and $\rho_{\mathrm{p}}$ is the intensity of the internal thermal source. $A_{\mathrm{f}}(x)$ represents the cross-sectional area of the fin along the $x$ direction. $A_{\mathrm{f}}(x)=t_{\mathrm{a}} L$ for straight fin, and $A_{\mathrm{f}}(x)=t_{\mathrm{a}} L x / H$ for triangular fin. The boundary conditions for straight fin are $x=0, T=T_{\mathrm{f}}$ and $x=H, \mathrm{~d} T / \mathrm{d} x=0$. The boundary conditions for straight fin are $x=0, T \neq \infty$ and $x=H$, $T=T_{\mathrm{f}}$. According to Fig. 7, the thermal power losses on $\mathrm{d} x$ are as follows:

$$
\begin{aligned}
\Delta P_{\mathrm{c}} & =\left|P_{x}-P_{x+\mathrm{d} x}\right|=\rho_{\mathrm{p}} L t_{\mathrm{a}}(x) \mathrm{d} x \\
& =h c_{1} C\left(T-T_{\mathrm{a}}\right) \mathrm{d} x \approx 2 h c_{1} L\left(T-T_{\mathrm{a}}\right) \mathrm{d} x
\end{aligned},
$$

where $C$ is the perimeter of the fin, which approximately equals $2 L ; t_{\mathrm{a}}(x)$ is the function of the fin thickness along $x$ direction; $t_{\mathrm{a}}(x)=t_{\mathrm{a}}$ for straight fin; and $t_{\mathrm{a}}(x)=t_{\mathrm{a}} x / H$ for triangular fin. According to Eq. (10),

$$
\rho_{\mathrm{p}}=2 h c_{1}\left(T-T_{\mathrm{a}}\right) / t_{\mathrm{a}}(x) .
$$

The function of the fin temperature $T$ along the $x$ direction can be obtained by uniting Eq. (9), Eq. (11), and $t_{\mathrm{a}}(x)$, and it will be denoted by $T(x)$. According to $T(x)$ and the expression of the Fourier's law shown in Eq. (12), the efficiency expressions of the rectangular striped fin and the triangular striped fin can be obtained, as shown respectively in Eqs. (12) and (13).

$$
\begin{gathered}
P=-k_{\mathrm{f}} L t_{\mathrm{a}}(x) \cdot \mathrm{d} T / \mathrm{d} x \\
\eta_{\mathrm{f}}=\frac{P}{P_{0}}=\frac{\operatorname{th}\left(\sqrt{2} \sqrt{h c_{1} /\left(k_{\mathrm{f}} A_{\mathrm{V}}\right)} H^{3 / 2}\right)}{\sqrt{2} \sqrt{h c_{1} /\left(k_{\mathrm{f}} A_{\mathrm{V}}\right)} H^{3 / 2}}, A_{\mathrm{V}}=t_{\mathrm{a}} H \\
\eta_{\mathrm{f}}=\frac{P}{P_{0}}=\frac{I_{1}\left(2 \sqrt{h c_{1} /\left(k_{\mathrm{f}} A_{\mathrm{V}}\right)} H^{3 / 2}\right)}{I_{0}\left(2 \sqrt{h c_{1} /\left(k_{\mathrm{f}} A_{\mathrm{V}}\right)} H^{3 / 2}\right)}, \quad A_{\mathrm{V}}=t_{\mathrm{a}} H / 2
\end{gathered}
$$

In Eqs. (13) and (14), $P$ represents the actual thermal dissipation of the fin, and $P_{\mathrm{o}}$ represents the thermal dissipation when the fin keeps the temperature in the root from the root to the terminal. $I_{1}$ and $I_{0}$ represent the 1-order and 0 -order first-kind-modified Bessel functions respectively.

According to Eqs. (13) and (14), the efficiency curves of the striped fins shown in Fig. 8 can be obtained. Therefore, the efficiencies of the striped rectangular striped fin and the triangular striped fin can be obtained by evaluating the efficiency curves shown in Fig. 8. Calculating accurate results for the striped trapezoidal fin is difficult. The efficiency can be replaced by the average value of the triangular striped fin efficiency and the rectangular striped fin efficiency when $A_{\mathrm{V}}=\left(t_{\mathrm{a}}+t_{\mathrm{m}}\right) H / 2$ is used. $t_{\mathrm{m}}$ represents the thickness of the terminal of the trapezoidal fin. When $c_{1}=1$, Eq. (13), Eq. (14), and Fig. 8 can also be used to calculate the efficiencies of smooth fins.

\section{Heat Transfer Coefficient}

Heat transfer coefficient $h$ is the key parameter in calculating Eqs. (4), (6), and (7), as well as the function of the Nusselt 


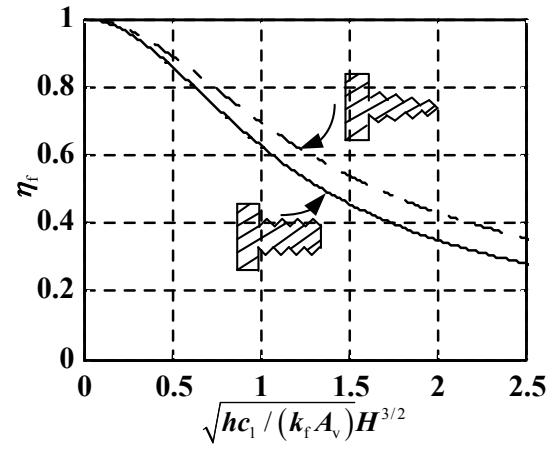

Fig. 8. Efficiency curves of striped fins.

number, $N u$. Unless otherwise stated, $h=N u k_{\mathrm{a}} / s$ is considered in the following sections, and $k_{\mathrm{a}}$ is the air thermal conductivity. This section focuses on the calculation of $\mathrm{Nu}$.

Air flows in the heat sink. Air flow can be divided into developing flow, transition, and fully developed sections. Except for special specifications in the following sections, $R e=V_{\mathrm{a}} s / v$, where $V_{\mathrm{a}}$ is the air velocity, and $v$ is the kinematic viscosity. Before analysis, $x^{+}=R e \cdot s / L$ and $x^{*}=R e \cdot \operatorname{Pr} \cdot s / L$ are defined, where $\operatorname{Pr}$ is the Prandtl number, and $P r$ is approximately equal to 0.7 for air.

1) Developing Flow Section: For the developing flow section, Refs. [11] and [12] adopted the expression shown in Eq. (15), Ref. [13] adopted the expression shown in Eq. (16), Ref. [18] adopted the expression shown in Eq. (17), and Refs. [14] and [15] adopted the expressions shown in Eq. (18).

$$
\begin{gathered}
N u=0.664 \sqrt{x^{+}} \operatorname{Pr}^{1 / 3}\left(1+3.65 / \sqrt{x^{+}}\right)^{1 / 2} \\
N u=2 N u^{\prime}, N u^{\prime}=1.89+\frac{0.142 \operatorname{Pr}^{1 / 3}\left(0.25 x^{+}\right)^{1.14}}{1+0.211\left(0.25 x^{+}\right)^{0.64}} \\
N u=1.86(\operatorname{Re} \operatorname{Pr} d / L)^{1 / 3} \cdot\left(\eta_{\mathrm{a}} / \eta_{\mathrm{h}}\right)^{0.14}, \operatorname{Re} \operatorname{Pr} d / L>10 \\
h=\frac{m_{\mathrm{a}} c_{\mathrm{a}}}{A_{\mathrm{a}}}\left(1-e^{-N T U}\right), m_{\mathrm{a}}=\rho_{\mathrm{a}} V_{\mathrm{amax}} W H, \\
N T U=h_{\mathrm{LMTD}} \frac{A_{\mathrm{a}}}{m_{\mathrm{a}} c_{\mathrm{a}}}, h_{\mathrm{LMTD}}=\frac{N u_{\mathrm{LMTD}}{ }^{\prime} k_{\mathrm{a}}}{2 s} \\
N u_{\mathrm{LMTD}}{ }^{\prime}=7.43237+0.0405984 \cdot 4 x^{*}-1.17060 \cdot 10^{-4} \cdot\left(4 x^{*}\right)^{2} \\
+2.42627 \cdot 10^{-7} \cdot\left(4 x^{*}\right)^{3}-13.1211(s / H) \\
0<\frac{s}{H}<\frac{1}{6}
\end{gathered}
$$

When only one channel of fins is analyzed, Eq. (18a) can be simplified as follows:

$$
N u=2 x^{*}\left(1-e^{-N u_{\mathrm{LMTD}} / x^{*}}\right) .
$$

In Eqs. (15)-(18), $d$ is the equivalent hydraulic diameter of the conduit, $N T U$ is the number of transfer units, and $A_{\mathrm{a}}$ is the total surface area of the heat sink. $\eta_{\mathrm{a}}$ is the viscosity of the air under the inlet and the outlet average air temperatures, and $\eta_{\mathrm{h}}$ is the viscosity of air under the fin surface temperature. This study considers that $\eta_{\mathrm{a}}=\eta_{\mathrm{h}} . \rho_{\mathrm{a}}$ is the air density. $V_{\mathrm{amax}}$ is the maximum velocity of the air flow between fins, and is approximately twice the average velocity of $V_{\mathrm{a}}$.

2) Fully Developed Section: For the fully developed section, Ref. [11] adopted the expression shown in Eq. (19), and Ref. [13] adopted the expression shown in Eq. (20).

$$
\left\{\begin{array}{c}
N u=x^{*} / 2 \\
N u=2 \cdot \frac{1-\mathrm{e}^{-N u_{s}^{\prime} /\left(0.25 x^{*}\right)}}{N u_{s}^{\prime} /\left(0.25 x^{*}\right)} N u_{s}^{\prime} \\
N u_{s}^{\prime}=1.89+\frac{0.142 \operatorname{Pr}^{1 / 3} \times\left(0.25 x^{+}\right)^{1.14}}{1+0.211\left(0.25 x^{+}\right)^{0.64}}
\end{array}\right.
$$

3) Composite Mode: To facilitate the calculation, Refs. [11] and [13] proposed $N u$ expressions shown as Eqs. (21) and (22) respectively; such expressions can be applied in the developing flow, transition, and fully developed sections.

$$
\begin{aligned}
& N u=\left\{\left(\frac{x^{*}}{2}\right)^{-3}+\left[0.664 \sqrt{x^{+}} \operatorname{Pr}^{1 / 3}\left(1+3.65 / \sqrt{x^{+}}\right)^{1 / 2}\right]^{-3}\right\}^{-1 / 3} \\
& N u=2 \cdot \frac{1-\mathrm{e}^{-1.89 /\left(0.25 x^{*}\right)}}{1.89 /\left(0.25 x^{*}\right)}\left\{1.89+\frac{0.142 \operatorname{Pr}^{1 / 3}\left(0.25 x^{+}\right)^{1.14}}{1+0.211\left(0.25 x^{+}\right)^{0.64}}\right\}
\end{aligned}
$$

4) Engineering Expression of $\mathrm{Nu}: \mathrm{Nu}$ expressions are complex in Eqs. (15)-(22). Therefore, the engineering expression shown in Eq. (23) is introduced by mathematically fitting $\mathrm{Nu}$ expressions proposed in Refs. [11]-[18]. This expression is suitable for the process from the developing flow section to the fully developed section, and it is concise and easy to calculate.

$$
N u=\left[23.4\left(x^{+}\right)^{-3}+\left(x^{+}\right)^{-1.28}\right]^{-1 / 3}
$$

The heat transfer coefficient $h$ can be obtained by using Eq. (23), $x^{+}=R e \cdot s / L$, and $h=N u k_{\mathrm{a}} / s$.

To compare the error of Eq. (23), the curves of $N u$ shown in Fig. 9 are drawn according to Eqs. (15)-(18) and Eqs. (21)-(23) of the developing flow section; the curves of $N u$ shown in Fig. 10 are drawn according to Eqs. (19)-(23) of the fully developed section. For comparison, $\operatorname{Pr}$ is 0.7 when drawing Figs. 9 and 10 , and $d=s$ is approximately taken. The curve of Eq. (18) represents only one channel of fins. In Fig. 9, given that the upper limit range of the curve of Eq. (18) is $\operatorname{Re}: s / L=125$, no reference value is used when crossing the border [14], [15]. The expressions of the developing flow section shown in Eqs. (15)-(18) are valid only when it takes approximately $R e \cdot s / L>20$. The expressions of the fully developed section shown in Eqs. (19) and (20) are valid only when they utilize approximately $\operatorname{Re}: s / L<3$.

As shown in Figs. 9 and 10, the curves of Eq. (23) are 


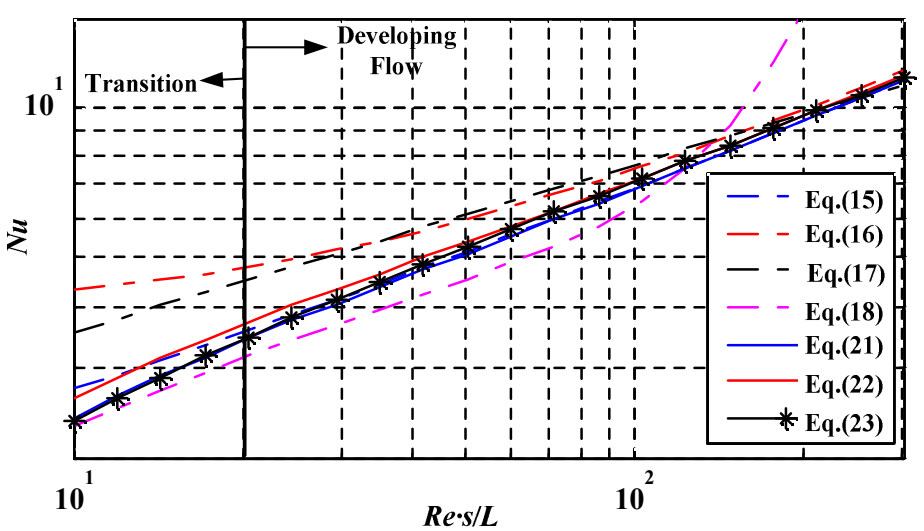

Fig. 9. $N u$ of the developing flow section.

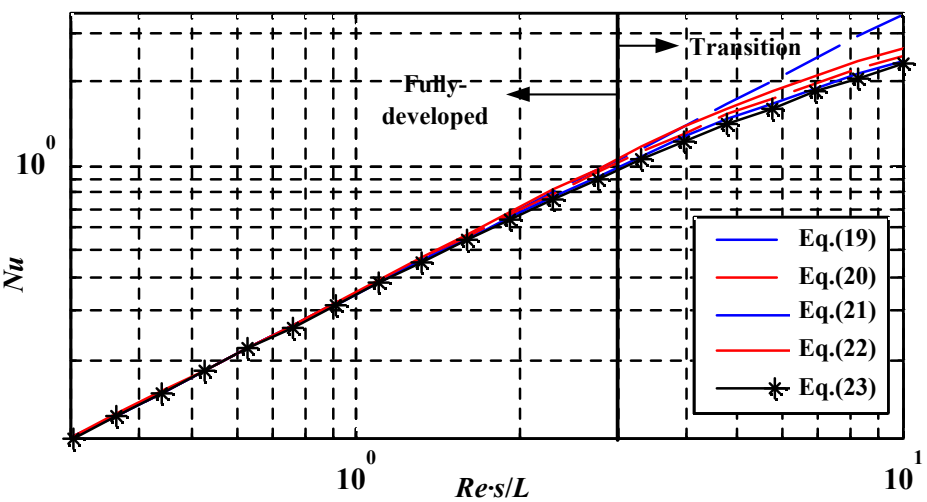

Fig. 10. $N u$ of the fully developed section.

located among the curves of Eqs. (15)-(18), (21), and (22) in the developing flow section, that is, when $\operatorname{Re}: s / L>20$. The curve of Eq. (23) is slightly lower than those of Eqs. (19)-(22) in the fully developed section, that is, when $\operatorname{Re}: s / L<3$. The curve of Eq. (23) is insignificantly lower than those of Eqs. (21) and (22) in the transition section, that is, when $3<\operatorname{Re}: \mathrm{s} / L<20$.

According to the preceding analysis, the complexity of Eq. (23) is significantly lower than that of existing expressions. Meanwhile, the accuracy is only slightly lower than that of existing expressions.

\section{Pressure Drop of Heat Sink}

The frictional air pressure drop in a heat sink can directly influence the volumetric flow rate of the fan, which is related to the effect of the air-cooled design. This section investigates the frictional air pressure drop of heat sinks.

Heat sink causes the total pressure drop, as follows:

$$
\Delta p_{\mathrm{a}}=\Delta p_{\mathrm{c}}+\Delta p_{1},
$$

where $\triangle p_{1}$ represents the sum of the inlet and outlet pressure drop, and $\triangle p_{\mathrm{c}}$ represents the core pressure drop. $\triangle p_{1}$ is

$$
\left\{\begin{array}{l}
\Delta p_{1}=\left(K_{\mathrm{c}}+K_{\mathrm{e}}\right) \rho_{\mathrm{a}} V_{\max }^{2} / 2 \\
K_{\mathrm{c}}=0.8-0.4 \varepsilon^{2} \\
K_{\mathrm{e}}=(1-\varepsilon)^{2}-0.4 \varepsilon \\
\varepsilon=s /\left(s+t_{\mathrm{a}}\right)
\end{array} .\right.
$$

$\Delta p_{\mathrm{c}}$ is

$$
\Delta p_{\mathrm{c}}=\left[4 f_{\mathrm{app}} \cdot 2 \operatorname{Re} /\left(4 x^{+}\right)\right]\left(\rho_{\mathrm{a}} V_{\mathrm{a} \max }^{2} / 2\right) .
$$

where $f_{\text {app }}$ is the apparent friction factor. The calculation of $2 f_{\text {app }} R e$ in Refs. [14] and [15] adopted Eq. (27), and Ref. [16] adopted Eq. (28). For high-power cooling fins, $s / H<1 / 6$ generally, and Eqs. (27) and (28) are similar. Therefore, $\Delta p_{\mathrm{c}}$ can be calculated with either of the following equations:

$$
\begin{aligned}
2 f_{\text {app }} R e= & 23.7366+0.219847 \times\left(4 x^{+}\right) \\
& -6.43526 \times 10^{-3} \times\left(4 x^{+}\right)^{1.5}+7.39124 \times 10^{-5} \times\left(4 x^{+}\right)^{2}, \\
& -3.81290 \times 10^{-9} \times\left(4 x^{+}\right)^{3}
\end{aligned}
$$

$$
\left\{\begin{array}{rl}
2 f_{\text {app }} R e=\left[\left(3.44 \sqrt{4 x^{+}}\right)^{2}+(2 f R e)^{2}\right]^{1 / 2} \\
2 f R e= & 24-32.527\left(\frac{s}{H}\right)+46.721\left(\frac{s}{H}\right)^{2} \\
& -40.829\left(\frac{s}{H}\right)^{3}+22.954\left(\frac{s}{H}\right)^{4}-6.089\left(\frac{s}{H}\right)^{5}
\end{array},\right.
$$

where $f$ is the friction factor.

\section{E. Fan Characteristics}

For fans, the relationship between volumetric flow rate and 


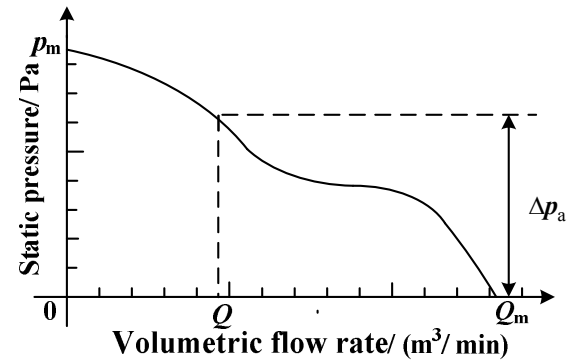

Fig. 11. Relationship between volumetric flow rate and static pressure.

static pressure is shown in Fig. 11 [27]. This figure is generally given in the fan specification. When the total pressure drop of the heat sink is $\triangle p_{\mathrm{a}}$, the corresponding actual volumetric flow rate is shown as $Q$ in Fig. 11. $Q_{\mathrm{m}}$ and $p_{\mathrm{m}}$ in Fig. 11 represent the rated volumetric flow rate and the rated static pressure of the fan respectively.

According to Ref. [28], the following equation is reasonable to some extent:

$$
n / n_{\mathrm{m}}=Q / Q_{\mathrm{m}}=\sqrt{p / p_{\mathrm{m}}}=\sqrt[3]{N / N_{\mathrm{m}}},
$$

where $n, p$, and $N$ represent the rotational speed, static pressure, and shaft power of the fan, respectively. The subscript $\mathrm{m}$ represents the rated value. Therefore, Eq. (29) and the given parameters in the fan specification can be used to estimate the fan performance.

The relationship between the actual volumetric flow rate $Q$ and the thermal dissipation power $P$ of the fan is shown in Eq. (30). This equation can be used to estimate the volumetric flow rate of the fan. The unit of $Q$ in Eq. (30) is $\mathrm{m}^{3} / \mathrm{min}$, and the other variables use System International units.

$$
Q=60 P /\left(\rho_{\mathrm{a}} c_{\mathrm{a}} \Delta T_{\mathrm{a}}\right),
$$

where $c_{\mathrm{a}}$ is the specific heat capacity of air with a value of $1000 \mathrm{~J} /\left(\mathrm{kg} \cdot{ }^{\circ} \mathrm{C}\right) . \quad \rho_{\mathrm{a}}=1.20 \mathrm{~kg} / \mathrm{m}^{3}$ at $20{ }^{\circ} \mathrm{C} . \quad \Delta T_{\mathrm{a}}$ is the temperature difference between inlet and outlet air. The outlet temperature should not be higher than $71{ }^{\circ} \mathrm{C}$.

When the power is relatively high, a single fan generally cannot provide thermal dissipation. Several fans running together are needed. Fans in series mainly change the air pressure, and fans in parallel mainly change the volumetric flow rate. Therefore, if the total pressure drop of the heat sink is relatively high, the series operation will be efficient. If the volumetric flow rate is insufficient, the parallel operation will be efficient.

For fans with the same size, their volumetric flow rate and air pressure differ [20], and the effect of thermal dissipation has a great difference. Therefore, fans with medium performance should be adopted for an air-cooled design. Replacing medium-performance fans with high-performance fans that have the same size is simple and efficient if the air-cooled design cannot meet the requirements.

\section{F. Air-cooled Design Process}

1) Losses should be calculated according to the methods in

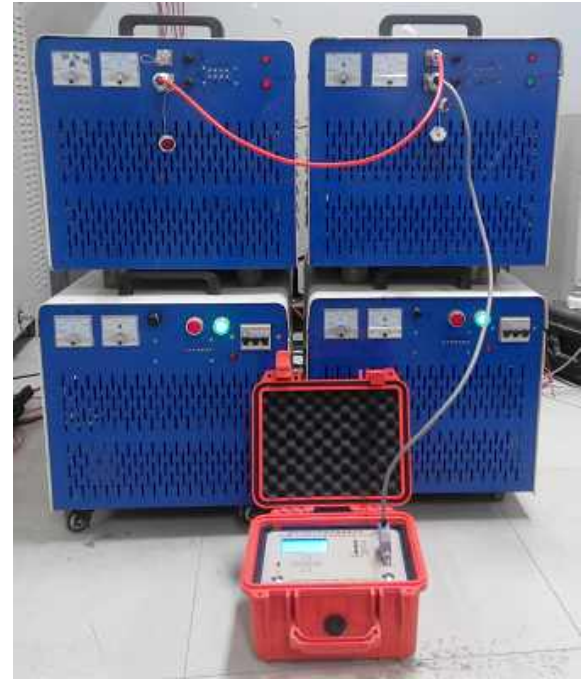

Fig. 12. Photo of a $40 \mathrm{~kW}$ transmitter.

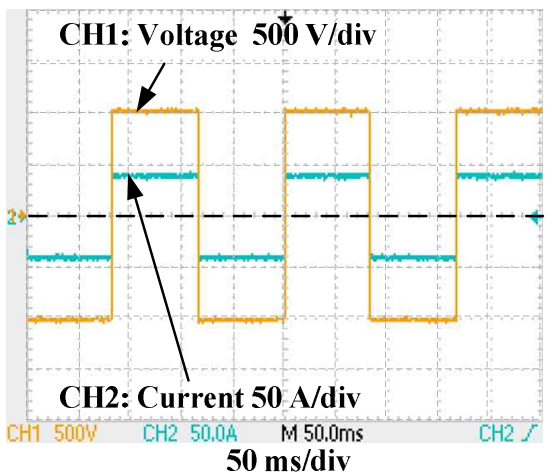

Fig. 13. Output voltage and current waveforms.

Section III.B. Different topologies have different switching losses.

2) A heat sink should be selected first. $N u$ should be calculated according to Eq. (23) with an air velocity of $4 \mathrm{~m} / \mathrm{s}$, and the heat transfer coefficient $h$ should then be obtained.

3) Fin efficiency should be calculated according to the method in Section IV.B.

4) Thermal resistance should be calculated according to the method in Section IV.A.

5) Pressure drop of the heat sink should be calculated according to the method in Section IV.D.

6) On the basis of the pressure drop of the heat sink and the thermal dissipation power, fans should be chosen according to the method in Section IV.E. Whether the selected air velocity is reasonable should be examined.

7) If the thermal design cannot meet the requirements, whether to replace heat sink, change the air velocity, or make fans in series or in parallel should be considered. The thermal design should be calculated again according to steps 2)-6).

8) Power devices should be appropriately arranged, and the thermal power should be evenly distributed on the heat 


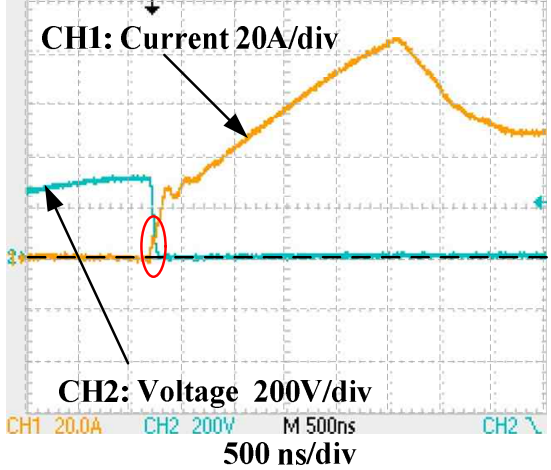

(a)

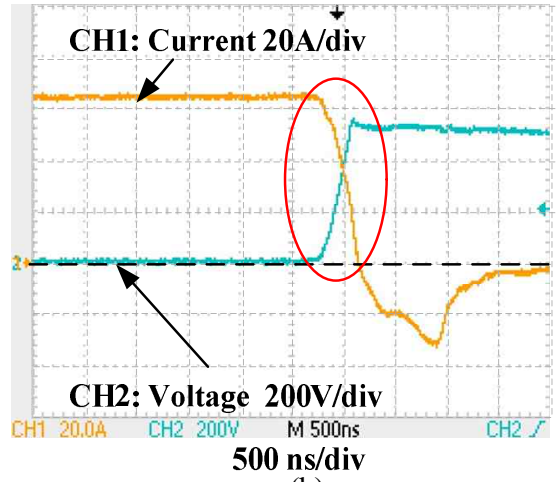

(b)

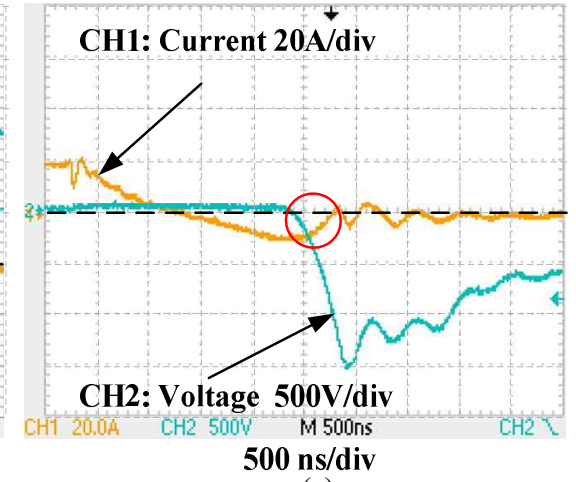

(c)

Fig. 14. Transition waveforms in AC-DC power supply. (a) $\mathrm{VT}_{1}$ turn-on waveforms. (b) $\mathrm{VT}_{1}$ turn-off waveforms. (c) $\mathrm{D}_{1}$ reverse recovery waveforms.

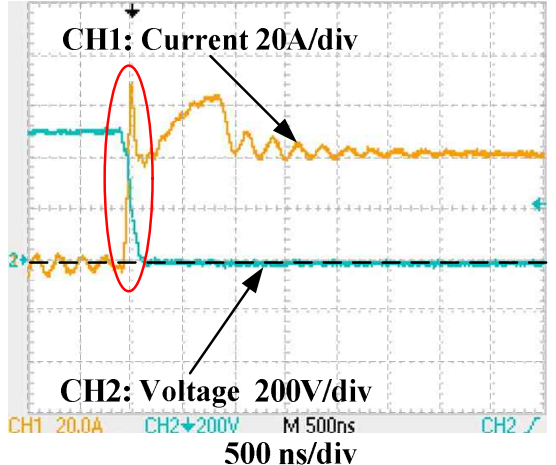

(a)

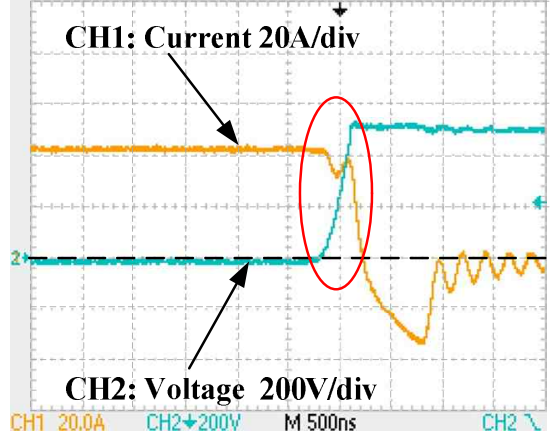

$500 \mathrm{~ns} / \mathrm{div}$

(b)

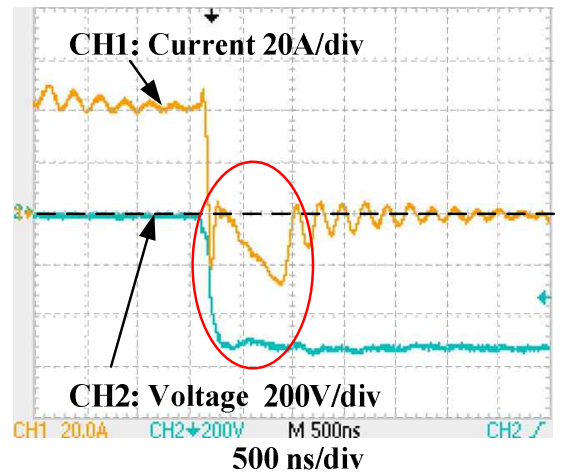

(c)

Fig. 15. Transition waveforms in constant-current circuit. (a) $\mathrm{VT}_{2}$ turn-on waveforms. (b) $\mathrm{VT}_{2}$ turn-off waveforms. (c) $\mathrm{D}_{2}$ reverse recovery waveforms.

sink.

9) The air duct should be designed.

\section{MEASURED RESULTS}

\section{A. Experimental Conditions}

The transmitter runs $8 \mathrm{~h}$ a day at $40 \mathrm{~kW}$ and operates normally after working for three days. Fig. 12 shows a photo of the working transmitter at $40 \mathrm{~kW}$. Fig. 13 shows the output voltage and current waveforms after thermal stabilization. Fig. 13 shows that the output voltage is more than $1000 \mathrm{~V}$, the current is more than $40 \mathrm{~A}$, and the total output power is more than $40 \mathrm{~kW}$. During the test, waveforms are obtained by using a TDS2012C oscilloscope. The current waveform in Fig. 13 is obtained by using a current probe A622, and the current waveforms in Figs. 14 and 15 are obtained by measuring the voltage on $0.1 \Omega$ resistance. Current values are measured with the oscilloscope. Voltage is obtained by using a UT39A multimeter. Temperature is obtained by using an ST380 infrared thermometer, and the resolution of the infrared thermometer is $1^{\circ} \mathrm{C}$.

\section{B. Transmitter Losses}

Fig. 14 shows the turn-on and turn-off waveforms of $\mathrm{VT}_{1}$, and the reverse recovery waveforms of $\mathrm{D}_{1}$ in $\mathrm{AC}-\mathrm{DC}$ power supply. The overlapping area of $i_{\mathrm{VT} 1}$ and $v_{\mathrm{VT} 1}$ in Fig. 14(a) is small, that of $i_{\mathrm{VT} 1}$ and $v_{\mathrm{VT} 1}$ in Fig. 14(b) is large, and that of $i_{\mathrm{D} 1}$ and $v_{\mathrm{D} 1}$ in Fig. 14(c) is small, which are the same as in Fig. 3(a). The overlapping area in Figs. 14(a) and 14(c) are small because the leakage inductance of the transformer in AC-DC power supply limits the change rate of the current. The overlapping area in Fig. 14(b) is large because the current in the leakage inductance of the transformer can only flow through $\mathrm{VT}_{1}$ before $v_{\mathrm{VT} 1}$ up to the bus voltage.

Fig. 15 shows the turn-on and turn-off waveforms of $\mathrm{VT}_{2}$, and the reverse recovery waveforms of $\mathrm{D}_{2}$ in constant-current circuit. The overlapping areas in Fig. 15(a)-15(c) are large, the same as in Fig. 3(b). The overlapping area in Fig. 15(a) is large because the voltage is clamped to the bus voltage before the current up to the inductance current. The overlapping area in Fig. 15(b) is large because the current is clamped to the inductance current before the voltage up to the bus voltage. Given that the change rate of $i_{\mathrm{D} 2}$ from $40 \mathrm{~A}$ to $0 \mathrm{~A}$ is fast, which is determined by the change rate of $i_{\mathrm{VT} 2}$ from $0 \mathrm{~A}$ to $40 \mathrm{~A}$, the overlapping area in Fig. 15(c) is large.

The turn-off loss of $\mathrm{VT}_{1}$, the turn-on loss and turn-off loss of $\mathrm{VT}_{2}$, and the reverse recovery loss of $\mathrm{D}_{2}$ can be calculated using Eq. (1). However, the turn-on loss of $\mathrm{VT}_{1}$ and the reverse recovery loss of $\mathrm{D}_{1}$ are only small parts of Eq. (1) and cannot be calculated using the equation. Therefore, when 
TABLE V

MEASURED Loss DATA

\begin{tabular}{|c|c|c|c|}
\hline & $\boldsymbol{P}_{\mathbf{1}}$ & $\boldsymbol{P}_{\mathbf{2}}$ & $\boldsymbol{P}_{\mathbf{3}}$ \\
\hline Voltage (V) & 490 & 524 & 500 \\
\hline Current (A) & 43.4 & 38.0 & 38.4 \\
\hline
\end{tabular}

TABLE VI

EFFiCIENCY of CAlCUlated ANd MEASURed VAlues

\begin{tabular}{|c|c|c|c|}
\hline Efficiency & $\boldsymbol{\eta}_{\mathbf{1}}$ & $\boldsymbol{\eta}_{\mathbf{2}}$ & $\boldsymbol{\eta}$ \\
\hline Calculated value & $94.2 \%$ & $97.0 \%$ & $91.4 \%$ \\
\hline Measured value & $93.6 \%$ & $96.4 \%$ & $90.2 \%$ \\
\hline
\end{tabular}

switching losses are calculated, the circuit topologies should be considered.

The bus voltage and current value after $50 \mathrm{~Hz}$ rectifier $\mathrm{U}_{1}$ are measured to approximately calculate the input power of the AC-DC power supply, which is represented as $P_{1}$ in Table V. The output voltage and current of the AC-DC power supply are measured to approximately calculate the output power of the AC-DC power supply, which is represented as $P_{2} . P_{2}$ also represents the input power of the constant-current circuit. The bus voltage and current values between short-circuit protection circuit $Z_{1}$ and output full-bridge $Z_{2}$ are measured to approximately calculate the output power of the constant-current circuit, which is represented as $P_{3}$. The test results are shown in Tables $\mathrm{V}$ and VI. To compare the error of loss calculation, the calculated value of the efficiency of the AC-DC power supply, represented as $\eta_{1}$, in Table VI excludes the losses of $50 \mathrm{~Hz}$ rectifier bridge $U_{1}$ and the losses of the input contactor $U_{8}$. The calculated value of the constant-current circuit efficiency, represented as $\eta_{2}$, excludes the losses of the output full-bridge $Z_{2}$ and its $R C$ snubber $Z_{2 R}$ from Table IV. The efficiency of the transmitter, represented as $\eta$, is determined by the product of $\eta_{1}$ and $\eta_{2}$.

The results in Table VI show that the deviation between calculated value of the transmitter and measured value is $1.2 \%$; the calculation deviation of losses is $1.2 /(100-90.2) \times 100 \%=12.2 \%$. The error is reasonable. The proposed thermal loss calculation method in this study is effective and feasible.

\section{Temperature Rise of Heat Sink}

According to this analysis, a heat sink, SRX-YTJ, with striped rectangular fins is adopted as the heat sink of the AC-DC power supply with parameters of $s=4.8 \mathrm{~mm}$, $t_{\mathrm{a}}=2.5 \mathrm{~mm}, t_{\mathrm{b}}=13 \mathrm{~mm}, c_{1}=2, H=62 \mathrm{~mm}, L=350 \mathrm{~mm}$, $W=360 \mathrm{~mm}, n_{\mathrm{f}}=49$, and $k_{\mathrm{f}}=160 \mathrm{~W} /\left(\mathrm{m} \cdot{ }^{\circ} \mathrm{C}\right)$. Three parallel fans are adopted for thermal dissipation. The fan model is FFC1212DE, which has the parameters $Q_{\mathrm{m}}=5.38 \mathrm{~m}^{3} / \mathrm{min}$, $p_{\mathrm{m}}=170 \mathrm{~Pa}$, and $N_{\mathrm{m}}=29 \mathrm{~W}$. The temperature of the five test points are measured on the heat sink of the AC-DC power supply shown in Fig. 16, and the results are shown in Table VII. The representation of the devices $\mathrm{U}_{1}, \mathrm{U}_{2}, \mathrm{U}_{2 \mathrm{R}}, \mathrm{U}_{4}, \mathrm{U}_{4 \mathrm{R}}$,

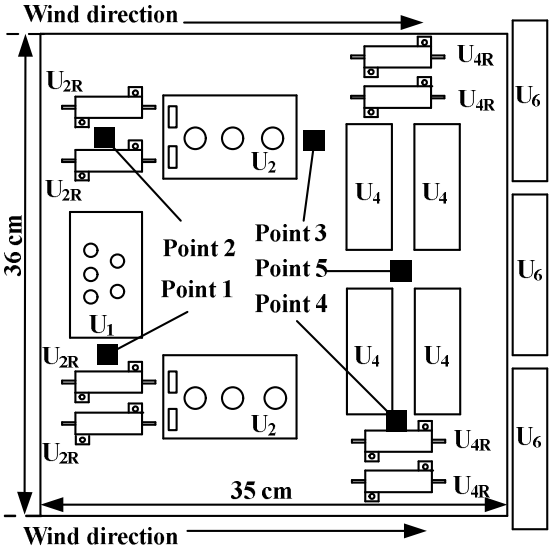

Fig. 16. Distribution of measured points.

TABLE VII

TEMPERATURE OF THE HEAT SinK

\begin{tabular}{|c|c|c|c|c|c|}
\hline Point & 1 & 2 & 3 & 4 & 5 \\
\hline Temperature $\left({ }^{\circ} \mathbf{C}\right)$ & 37 & 57 & 44 & 37 & 38 \\
\hline
\end{tabular}

and $\mathrm{U}_{6}$ is indicated in Table III. The ambient temperature is $21{ }^{\circ} \mathrm{C}$. Table VII shows that the average temperature rise is $22{ }^{\circ} \mathrm{C}$, the temperatures of the five points are relatively even, and the design of the thermal dissipation is reasonable.

\section{CONCLUSIONS}

1) The rated voltage of IGBTs in the cascaded transmitter can be half of that in the integrated transmitter for adopting cascaded topology, which can reduce the switching losses of the transmitter. If the AC-DC power supply adopts constant-current control in future research, the constant current circuit in this study can be deleted and the transmitter losses reduced.

2) The full-bridge inverter IGBTs in the AC-DC power supply and the chopper switch IGBT in the constant-current circuit have different voltage and current transition waveforms. The high-frequency rectifier diodes in the AC-DC power supply and chopper diode in the constant-current circuit also have different reverse recovery voltage and current waveforms. The switching losses of the power devices should be calculated according to the topologies.

3) Striped fins mainly change the surface area of thermal dissipation. The thermal resistance of a heat sink with striped fins can be calculated by multiplying the heat transfer coefficient by a striped coefficient under the smooth fin model, and the striped coefficient can be calculated by dividing the total surface area of striped fins by the total surface area of the corresponding smooth fins. The heat sink can cause a frictional air pressure drop, while the volumetric flow rate of the fan decreases with the increase in pressure drop. Therefore, the effect of pressure drop of the heat sink should be 
considered. Medium-performance fans should be adopted for an air-cooled design. Replacing medium-performance fans with high-performance fans that have the same size is simple and efficient if the air-cooled design cannot meet the requirements.

4) The measured results show that the deviation between calculated value and measured value of the transmitter losses is $12.2 \%$, which meets the error design requirements of less than $25 \%$. The temperature of each point on the heat sink of AC-DC power supply is roughly even, and the average temperature of the heat sink is $22{ }^{\circ} \mathrm{C}$, which meets the design requirements of the temperature rise between $20{ }^{\circ} \mathrm{C}$ and $40^{\circ} \mathrm{C}$. The transmitter has favorable thermal stability with an output power of $40 \mathrm{~kW}$.

5) To some extent, the proposed air-cooled design can be used in other power electronic equipment below $100 \mathrm{~kW}$.

\section{REFERENCES}

[1] Z. G. An, Q. Y. Di, C. M. Fu, C. Xu, and B. Cheng, "Geophysical evidence through a CSAMT survey of the deep geological structure at a potential radioactive waste site at Beishan, Gansu, China," J. Environ. Eng. Geophys., Vol. 18, No. 1, pp. 43-54, Mar. 2013.

[2] G. J. Wu, X. Y. Hu, G. P. Huo, and X. C. Zhou, "Geophysical exploration for geothermal resources: an application of MT and CSAMT in Jiangxia, Wuhan, China," J. Earth Sci., Vol. 23, No. 5, pp. 757-767, Oct. 2012.

[3] S. B. Singh, G. A. Babu, B. Veeraiah, and O. P. Pandey, "Thinning of granitic-gneissic crust below uplifting Hyderabad granitic region of the eastern Dharwar Craton (South Indian Shield): evidence from AMT/CSAMT experiment," J. Geol. Soc. India, Vol. 74, No. 6, pp. 697-702, Dec. 2009.

[4] F. Yu and Y. M. Zhang, "Modeling and control method for high-power electromagnetic transmitter power supplies," Journal of Power Electronics, Vol. 13, No. 4, pp. 679-691, Jul. 2013.

[5] Q. Y. Jiang, "Study on the key technology of wide field electromagnetic sounding instrument," Ph.D. Thesis, Central South University, Changsha, China, 2010.

[6] Q. H. Zhen, Q. Y. Di, and H. B. Liu, "Key technology study on CSAMT transmitter with excitation control," Chinese J. Geophys., Vol. 56, No. 11, pp. 3751- 3760, Nov. 2013.

[7] F. S. Shi, "A study on high power multi-function transmitting system," Progress in Geophysics, Vol. 24, No. 3, pp. 1109-1114, Jun. 2009.

[8] P. R. Lin, P. Guo, F. S. Shi, C. J. Zheng, Y. Li, J. H. Li, and B. L. Xu, "A study of the techniques for large-depth and multi-functional electromagnetic survey," Acta Geoscientica Sinica, Vol. 31, No. 2, pp. 149-154, Apr. 2010.

[9] Z. Y. Zhang, G. Q. Xu, and X. L. Shen, "Analyzing and designing of dissipation system of inverter," Journal of Tongji University (Natural Science), Vol. 32, No. 6, pp. 775-778, Jun. 2004.
[10] W. Z. He, D. Y. Qiu, W. X. Xiao, and B. Zhang, "Thermal design of high frequency high power switched-mode power supply," Trans. China Electrotechnical Society, Vol. 28, No. 2, pp. 185-191,218, Feb. 2013.

[11] P. Teertstra, M. M. Yovanovich, and J. R. Culham, "Analytical forced convection modeling of plate fin heat sinks, "Journal of Electronics Manufacturing, Vol. 10, No. 4, pp. 253-261, Dec. 2000.

[12] T. Y. Kim and S. J. Kim, "Fluid flow and heat transfer characteristics of cross-cut heat sinks," Int. J. Heat Mass Transfer, Vol. 52, No. 23-24, pp. 5358-5370, Nov. 2009.

[13] Y. Sata, H. Iwasaki, and M. Ishizuka, "Development of prediction technique for cooling performance of finned heat sink in uniform flow," IEEE Trans. Compon. Packag. Manuf. Technol. Part A, Vol. 20, No. 2, pp. 160-166, Jun. 1997.

[14] S. Y. Kim and R. L. Webb, "Analysis of convective thermal resistance in ducted fan-heat sinks," IEEE Trans. Compon. Packag. Technol., Vol. 29, No. 3, pp. 439-448, Sep. 2006.

[15] S. W. Karng, J. H. Shin, H. S. Han, Y. H. Kim, and S. Y. Kim, "Thermal performance of a thermoelectric air-cooling system with heat sinks," in ITHERM, pp. 1-7, 2010.

[16] S. J. Kim, D. K. Kim, and H. H. Oh, "Comparison of fluid flow and thermal characteristics of plate-fin and pin-fin heat sinks subject to a parallel flow," Heat Transfer Eng., Vol. 29, No. 2, pp. 169-177, Feb. 2008.

[17] Z. P. Duan and Y. S. Muzychka, "Experimental investigation of heat transfer in impingement air cooled plate fin heat sinks," J. Electron. Packag., Vol. 128, No. 4, pp. 412-418, Dec. 2006.

[18] G. S. Dai, Heat Transfer, 2nd ed., Higher Education Press, Beijing, pp. 37-46, 255-258, 2011.

[19] J. Deans, J. Neale, W. Dempster, and C. K. Lee, "The use of effectiveness concepts to calculate the thermal resistance of parallel plate heat sinks," Heat Transfer Eng., Vol. 27, No. 5, pp. 56-67, Jun. 2006.

[20] DC Brushless Fans \& Blowers, http: //www.delta.com.tw /product /cp /dcfans /dcfans_main.asp, Oct. 5th 2014.

[21] D. W. Xu, H. W. Lu, L. P. Huang, S. Azuma, M. Kimata, and R. Uchida, "Power loss and junction temperature analysis of power semiconductor devices," IEEE Trans. Ind. Appl., Vol. 38, No. 8, pp. 1426-1431, Sep/Oct. 2002.

[22] K. Takao, and H. Ohashi, "Accurate power circuit loss estimation method for power converters with Si-IGBT and SiC-diode hybrid pair," IEEE Trans. Electron. Devices, Vol. 60, No. 2, pp. 606-612, Feb. 2013.

[23] A. Bhalla, J. Gladish, and G. Dolny, "Effect of IGBT switching dynamics on loss calculations in high speed applications," IEEE Electron Device Lett., Vol. 20, No. 1, pp. 51-53, Jan. 1999.

[24] K. Mylsamy, R. Vairamani, G. C. R. Irudayaraj, and H. T. R. Lawrence,"Experimental validation of a cascaded single phase H-bridge inverter with a simplified switching algorithm," Journal of Power Electronics, Vol. 14, No. 3, pp. 507-518, May 2014.

[25] W. A. Halim, N. A. Rahim, and M. Azri, "Selective harmonic elimination for a single-phase 13-level TCHB based cascaded multilevel inverter using FPGA," Journal of Power Electronics, Vol. 14, No. 3, pp. 488-498, May 2014.

[26] J. P. Lee, B. D. Min, and D. W. Yoo, "Implementation of a high efficiency grid-tied multi-level photovoltaic power 
conditioning system using phase shifted H-bridge modules," Journal of Power Electronics, Vol. 13, No. 2, pp. 296-303, Mar. 2013.

[27] M. F. Holahan, "Fins, fans, and form: volumetric limits to air-side heatsink performance," IEEE Trans. Compon. Packag. Technol., Vol. 28, No. 2, pp. 255-262, Jun. 2005.

[28] Y. B. Wu, M. S. Zhu, Engineering Fluid Mechanics Pump and Fan, Chemical Industry Press, Beijing, pp. 273-275, 2010.

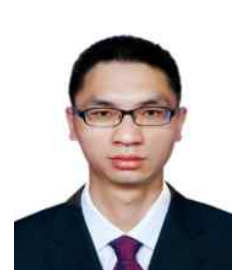

Kai-chang Xue was born in Yunnan, China in 1989. He received his B.S. in Electrical Engineering from Jilin University, Changchun, China in 2010. Currently, he is working toward his Ph.D. at the College of Instrumentation and Electrical Engineering, Jilin University, Changchun, China. His research area is impulse power supply of geophysic instrumentation.

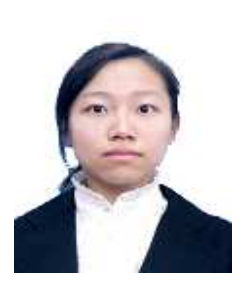

Shuang Wang was born in Jilin, China in 1989. She received her B.S. in Electrical Engineering from Jilin University, Changchun, China in 2013. She is currently working toward her M.S. at the College of Instrumentation and Electrical Engineering, Jilin University, Changchun, China. Her research areas are power electronic technology and application.

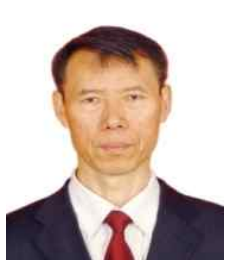

Jun Lin was born in Jilin, China in 1954. He received his B.S. and M.S. in Applied Geophysics from Changchun Geological Institute in 1982 and 1987 respectively. He is a professor and a Ph.D. supervisor at the College of Instrumentation and Electrical Engineering, Jilin University, Changchun, China. His research areas are geo-exploration technology and instrumentation, which include seismic instruments, electromagnetic instruments, and nuclear magnetic resonance instruments.

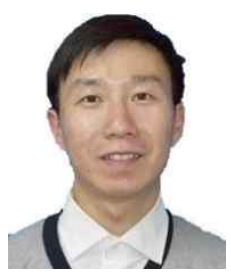

Gang Li was born in Hubei, China, in 1981. He received his B.S. and M.S. in Control Engineering from Central South University, Changsha, China in 2002 and 2005 respectively. He received his Ph.D. in Electrical Engineering from Tsinghua University, Beijing, China in 2009. He is currently a lecturer at the College of Instrumentation and Electrical Engineering, Jilin University, Changchun, China. His research interests include high-power converters, electrical machine drives, and explosion-proof inverters.

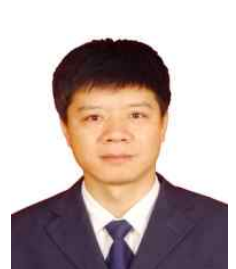

Feng-dao Zhou was born in Anhui, China in 1970. He received his B.S. in Electronic Measurement Technology and Instruments from Changchun Geological Institute in 1994, his M.S. in Instrument Science and Technology from Changchun University of Science and Technology in 1999, and his $\mathrm{Ph} . \mathrm{D}$. in Instrument Science and Technology from Jilin University in 2010. He is a Professor at the College of Instrumentation and Electrical Engineering, Jilin University, Changchun, China. His research areas are power electronic technology and application in land and marine electromagnetic prospecting instruments. 